\title{
МЕХАНИЗМЫ УЛУЧШЕНИЯ ИНВЕСТИЦИОННОГО КЛИМАТА АГРОПРОМЫШЛЕННОГО КОМПЛЕКСА РЕГИОНА
}

\section{MECHANISMS FOR IMPROVING THE INVESTMENT CLIMATE OF THE AGRO-INDUSTRIAL COMPLEX OF THE REGION}

\section{P. Stroev \\ R. Fattakhov \\ V. Matchinov \\ E. Gubanova \\ O. Orlovtseva}

Summary: The article presents analysis of the functioning of mechanisms and program measures aimed at improving the investment climate of the agro-industrial complex of the region. The priority directions forming the investment climate in the agro-industrial complex are justified: regulatory environment, information environment, institutions for business, infrastructure and resources, support for small and mediumsized businesses, support for foreign economic activity and exports. The best practices for improving the investment climate in the field of regional socio-economic development are analyzed. The results of the application of the presented tools in some regions of the Russian Federation are evaluated.

Keywords: agro-industrial complex, investment climate, region, state support, program.
Строев Павел Викторович

к.э.н., дочент, Финансовый университет при Правительстве Российской Федерации (г. Москва) stroevpavel@gmail.com

Фаттахов Рафаэль Валиахметович

д.э.н., профессор, г.н.С., Финансовый университет при Правительстве Российской Федерации (г. Москва) RFattakhov@fa.ru

Матчинов Виталий Анатольевич к.э.н., дочент, директор, Калужский филиал Финансового университета при Правительстве Российской Федерации

(2. Калуга)

VAMatchinov@fa.ru

Губанова Елена Витальевна

к.э.н., дочент, заместитель директора, Калужский филиал Финансового университета при Правительстве Российской Федерации (г. Калуга)

EVGubanova@fa.ru

Орловцева Оксана Михайловна

к.э.н., дочент, заместитель директора, Калужский филиал Финансового университета при Правительстве

Российской Федерации (г. Калуга)

OMOrlovtseva@fa.ru

Аннотация: В статье представлен анализ функционирования механизмов и программных мероприятий, направленных на улучшение инвестиционного климата агропромышленного комплекса региона. Обоснованы приоритетные направления, формирующие инвестиционный климат в агропромышленном комплексе: регуляторная среда, информационная среда, институты для бизнеса, инфраструктура и ресурсы, поддержка малого и среднего предпринимательства, поддержка внешнеэкономической деятельности и экспорта. Проанализированы лучшие практики по улучшению инвестиционного климата в области регионального социально-экономического развития. Оценены результаты применения представленных инструментов в некоторых субъектах Российской Федерации.

Ключевые слова: агропромышленный комплекс, инвестиционный климат, регион, государственная поддержка, программа.

казывает, что в настоящий момент инвестиционная политика агропромышленной сферы не в полной мере эффективна, существуют как определенные проблемы, так и потенциал для ее развития, что подтверждается исследованиями как ученых, так и экспертов [1, 2].

Следовательно, одной из приоритетных задач региональной политики является улучшение инвестиционного климата агропромышленного комплекса, привлечение дополнительных ресурсов в данную сферу. Ключевым инструментом, способствующим решению данной задачи, являются региональные программы, ос-

При этом практика регионального управления по- 
новная цель которых - создание фундамента для развития агропромышленного комплекса региона.

При планировании мероприятий в рамках региональных программ в качестве приоритетных направлений, формирующих инвестиционный климат в агропромышленном комплексе, следует выделить:

1. Регуляторная среда. Характеризует эффективность оказания государственных услуг и степень административного давления на бизнес [3, С. 102];

2. Информационная среда. Характеризует осведомленность предпринимателей и потенциальных инвесторов о требованиях законодательства, наличии мер поддержки, и других факторах, способных повлиять на ведение бизнеса [4, С. 157];

3. Институты для бизнеса. Характеризует наличие и качество инструментов защиты и улучшения инвестиционной среды;

4. Инфраструктура и ресурсы. Характеризует показатели работы и уровень развития инфраструктуры, а также доступность ресурсов для ведения бизнеса и инвестиционной деятельности [5, С. 53];

5. Поддержка малого и среднего предпринимательства. Характеризует уровень развития малого и среднего предпринимательства, а также эффективность различных видов его поддержки [6, C. 30];

6. Поддержка внешнеэкономической деятельности и экспорта. Характеризует наличие и эффективность инструментов поддержки экспорта продукции регионального АПК.

В последние годы вызывает большой интерес использование инструментов лучших практик в области регионального и муниципального социально-экономического развития. Использование лучших практик позволяет избежать типичных ошибок при реализации проектов и экономить ресурсы. В связи с этим представляется целесообразным рассмотреть ключевые мероприятия и программы, реализуемые в регионах России для того, чтобы применять на практике наиболее эффективные с учетом особенностей конкретного субъекта Российской Федерации.

Необходимо отметить, что общим для всех программ является создание электронной базы (далее - База), включающей все предприятия, ведущие деятельность в отрасли АПК, и их контактные данные. Своевременное и комплексное информирование является одним из основных факторов инвестиционного климата, что неоднократно отмечается Агентством стратегических инициатив [7]. Исходя из этого, цель создания Базы - это своевременное и комплексное информирование всех предприятий отрасли.

При этом необходимо подчеркнуть, что предлагаемые программы и их мероприятия в основной массе име- ют комплексное влияние как на различные компоненты, так и на направления, формирующие инвестиционный потенциал агропромышленного сектора экономики региона. В связи с этим, следует ожидать синергетического влияния и взаимного усиления эффективности в случае их одновременной реализации.

\section{Программа «Оптимизашия аАминистративно-регуляторной среАы»}

Цель данной программы состоит в повышении осведомленности, улучшении качества и снижении временных затрат для существующих предприятий и потенциальных инвесторов в вопросах законодательного, административного и надзорного регулирования деятельности АПК. Снижение временных затрат в свою очередь вызовет снижение расходов как на инвестиционной стадии, так и на стадии операционной деятельности, что напрямую повлияет на возврат инвестиций и рентабельность предприятий [8, С. 132].

Для достижения поставленных целей предлагаются следующие мероприятия:

1. Создание и размещение на официальном портале Правительства региона детального руководства по процедурам государственной регистрации бизнеса. Руководство должно включать все необходимые бланки документов с возможностью подачи и рассмотрения в электронном виде. В конечном итоге физическое посещение государственных учреждений должно быть сведено к 1 разу для конечной регистрации и с возможностью регистрации в любом отделении МФЦ. По данным этого руководства необходимо также подготовить бумажные буклеты для раздачи заинтересованным лицам;

2. Систематизация и размещение на официальном портале Правительства региона всех требований при проведении обязательных для АПК видов контроля с дополнением их утвержденными проверочными листами и возможностью обратной связи для оперативной консультации предпринимателей по возникшим вопросам. По данным этого руководства необходимо также подготовить бумажные буклеты для раздачи заинтересованным лицам;

3. Организация ежеквартальных публичных обсуждений представителями власти, предпринимателями и потенциальными инвесторами путей оптимизации взаимодействия с государственными органами, организации контрольно-надзорных мероприятий и качества их исполнения для увеличения прозрачности и исключения случаев административного давления на бизнес. Протоколирование, размещение на сайте и рассылка по Базе итогов проведенных обсуждений; 
4. Реализация в электронном виде: оформления ордеров на право земляных работ, разрешений на размещение объектов временного пользования, расширения необходимых предприятиям коммуникаций и других строительных процедур;

5. Формирование реестра и рейтинга кадастровых инженеров. Постановка на кадастровый учет относится к одной из наиболее затрудняющих бизнес-процессы услуг. Рейтинг должен учитывать качество и сроки выполнения кадастровых работ, в т. ч. количество приостановок и отказов в осуществлении государственного кадастрового учета объектов недвижимого имущества. Рейтинг направляется в общественные объединения и многофункциональные центры для широкого ознакомления предпринимателей и оказания помощи при выборе кадастрового инженера [9, С. 222];

6. Периодические проверки качества предоставляемых государственных услуг в формате «контрольной закупки».

Лучшие региональные практики: По итогам реализации мероприятий 2, 3 и 5 Ульяновская область более чем в 2 раза снизила уровень административного давления на бизнес по региональным видам государственного контроля. В Белгородской области также были организованы консультационные мероприятия, направленные на оптимизацию процедуры постановки на кадастровый учет, которые смогли уменьшить количество отказов.

В результате реализации мероприятия 3 в СанктПетербурге удалось структурировать и за год уменьшить количество необходимых видов контроля на $10 \%$ и общее число плановых проверок на 16,1\%, что привело к снижению административной нагрузки на бизнес и затраты государственных органов на их проведение. Также в этом регионе по итогам реализации мероприятия 4 было достигнуто снижение затрачиваемого на взаимодействие с ЕССК времени до 30\% по всем процедурам.

\section{Программа «Информационная поццер»ка АПК»}

Цель данной программы - это повышение осведомленности компаний и потенциальных инвесторов по максимально возможному числу вопросов, связанных с ведением бизнеса в АПК. Реализация программы позволит: региону увеличить объем инвестиций, а предприятиям улучшить бизнес-процессы, увеличить продажи и повысить рентабельность.

Для достижения поставленных целей предлагаются следующие мероприятия:

1. Составление и публикация ежегодного «Справочника сельскохозяйственного предпринимателя региона» с сопутствующей рекламной кампанией в СМИ. Справочник должен содержать необходимую информацию об основных бизнес-процессах, образцы документов, рекомендации по их составлению и набор лучших региональных практик, направленных на улучшение и оптимизацию деятельности в отрасли АПК. Электронная версия справочника должна быть размещена на портале государственных и муниципальных услуг, а также разослана по Базе;

2. Мониторинг, систематизация и оповещение о проводимых региональных и общегосударственных закупках продукции АПК. Сопровождение и консультирование предприятий, участвующих в соответствующих конкурсах;

3. Создание в качестве отдельного сервиса геоинформационной системы «Инвестиционная карта», позволяющей потенциальному инвестору найти подходящий проект или площадку, используя механизмы фильтрации и поиска в соответствии со своими предпочтениями [10, С. 34];

4. Организация или участие (в том числе вне региона) в инвестиционных конференциях и семинарах с освещением имеющихся в регионе инвестиционных проектов в отрасли АПК и потенциальных возможностей их расширения с электронной рассылкой обсуждаемых материалов. Привлечение предприятий, реализовавших или реализующих проекты для обсуждения их опыта;

5. Консультирование и сопровождение предприятий АПК в работе с различными финансовыми структурами по вопросам кредитования и привлечения финансирования, в том числе для крупных компаний по выходу на фондовый рынок.

Лучшие региональные практики: По итогам реализации мероприятия 1 в Белгородской области составлена электронная база 52 лучших предпринимательских практик, которая включает 19 практик, поддержанных государством и 33 практики, выделенные по итогам различных региональных конкурсов.

\section{Программа «Инфраструктура и основные фонАы Аля преАприятий АПК»}

Целью данной программы является обеспечение доступности и повышения качества инфраструктуры, а также создание условий для модернизации основных фондов предприятий АПК. Повышение технической оснащенности, доступности инфраструктуры может повлиять на все показатели производственного потенциала.

Для достижения поставленных целей предлагаются следующие мероприятия:

1. Создание экономически стабильным сельскохозяйственным организациям льготных условий для выкупа имущества предприятий-должников у его кредиторов с целью продолжения его использования в сельскохозяйственном производстве на 
территории региона. Данное решение позволит выводить убыточные и неэффективные компании с рынка, повышая одновременно с этим обеспеченность основными фондами прибыльных организаций [11, С. 110];

2. Освобождение от регионального налога на прибыль той её части, которая направляется на модернизацию основных фондов и техническое оснащение предприятий АПК;

3. Организация конкурсов на субсидирование части затрат на техническое оснащение предприятий АПК на базе анализа потенциального увеличения объёмов производства и/или снижения себестоимости [12, С. 23];

4. Комплексная инвентаризация государственного, муниципального и бесхозного имущества, включая земельные участки, которое может быть передано в пользование фермерским хозяйствам;

5. Строительство и ремонт автомобильных дорог с учетом реализуемых и планируемых инвестиционных проектов;

6. Регулярный мониторинг качества услуг ресурсообеспечивающих организаций с последующим публичным обсуждением;

7. Создание ресурса, содержащего информацию обо всех существующих и проектируемых подземных инженерных коммуникациях и сооружениях;

Лучшие региональные практики: Тюменская область в 2015 году ввела для обрабатывающих производство льготы в виде нулевой ставки регионального налога на прибыль для той ее части, которая расходуется на инвестиции в регионе, что позволило в течение первого года привлечь дополнительные 300 млн. рублей для этой отрасли народного хозяйства.

\section{Программа «Аоступные финансы А^я АПК»}

Цель программы - это увеличение объёмов доступного предприятиям АПК финансирования. Упрощение доступа к кредитам или совместная с государством реализация проектов напрямую повлияют как на появление новых проектов, так и на модернизацию старых.

Для достижения поставленных целей предлагаются следующие мероприятия:

1. Предоставление на конкурсной основе грантов или льгот компаниям, ведущим исследования или разработки в сфере АПК, в том числе селекция, создание собственного семенного фонда, методы повышения урожайности и др. Внедрение новых технологий может одновременно повысить конкурентоспособность региональных сельскохозяйственных предприятий и выступить самостоятельным коммерческим продуктом;

2. Формирование фермерских кооперативов. Ис- пользование схемы, реализуемой мировыми лидерами АПК, позволит мелким фермерским хозяйствам упрочить свои позиции. Создание кооперативов сделает малый фермерский бизнес более значимым и упростит получение господдержки. Это позволит решить проблему технологического разрыва между крупными агрохолдингами и малыми хозяйствами, основной причиной которого является низкая доступность кредитов для малого агробизнеса при одновременно высоких рисках инвестирования в него;

3. Предоставление государственных гарантий по кредитам выданным фермерским хозяйствам. При условии реализации этого пункта совместно с созданием фермерских кооперативов будут обеспечены благоприятные условия для привлечения финансирования [13, С. 61];

4. Предоставление на конкурсной основе государственного страхования инвестиций для проектов, имеющих наибольший финансово-экономический потенциал;

5. Субсидирование на конкурсной основе процентных ставок по кредитам, выданным предприятиям АПК;

6. Развитие института государственно-частного партнёрства (далее - ГЧП), в том числе для реализации проектов инфраструктурного обеспечения, в соответствии с федеральными Рекомендациями по реализации проектов государственно-частного партнерства в субъектах Российской Федерации и Методическими рекомендациями по развитию институциональной среды в сфере государственно-частного партнерства в субъекте РФ (Региональный ГЧП-стандарт). Создание специализированной структуры, ответственной за подготовку и сопровождение проектов ГЧП;

Лучшие региональные практики: Правительство Белгородской области выделило сельским предприятиям 100 млн. рублей на субсидирование затрат, связанных с оборудованием, услугами или работами, нацеленными на создание производства. В 2017 году портфель бизнес-проектов сельских территорий содержит 296 бизнес-идей с созданием более 2,1 тыс. рабочих мест и объемом инвестиций в указанные проекты свыше 5,7 млрд. рублей.

Представляется, что реализация рассматриваемых и иных программных мероприятий, направленных на улучшение инвестиционного климата агропромышленного комплекса в регионе с учетом специфики конкретного субъекта Российской Федерации, позволит не только повысить эффективность социально-экономического развития региона, но и поднять степень продовольственной безопасности страны в целом. 


\section{ЛИТЕРАТУРА}

1. Дикая Д.И., Буден Д.А., Воробьева Д.И., Габриэль Е.С. Инвестиционный климат в агропромышленном комплексе Краснодарского края // Colloquiumjournal. 2020. № 31-4 (83). С. 18-20.

2. Черникова С.А. Актуальные вопросы привлечения инвестиций в агропромышленный комплекс // Экономика АПК Предуралья. 2017. № 1. С. 81-87.

3. Фаттахов Р.В., Низамутдинов М.М., Орешников В.В. Оценка устойчивости социально-экономического развития регионов России // Мир новой экономики. 2019. Т. 13. № 2. С. 97-110.

4. Низамутдинов М.М., Орешников В.В. Информационная поддержка формирования стратегий инновационного развития регионов на основе адаптивной имитационной модели // Системы и средства информатики. 2018. Т. 28. № 2. С. 154-169.

5. Макар С.В., Строев П.В., Власюк Л.И. Тенденции, факторы развития реального сектора экономики и актуальные инструменты обеспечения: дорожное картирование для внутреннего инвестирования // Экономика. Налоги. Право. 2018. Т. 11. № 6. С. 50-56.

6. Лаптев С.В., Пивоварова 0.В. Проблемы финансовой автономии региональных бюджетов // В сборнике: Инновационное развитие российской экономики. VII Международный научно-практический форум, материалы конференции. 2014. С. $29-32$.

7. Сборник лучших региональных управленческих практик в сфере повышения инвестиционной привлекательности по результатам Национального рейтинга состояния инвестиционного климата в субъектах Российской Федерации 2018 года // URL: https://asi.ru/upload/upload_docs/investclimate/ BestPractices2018.pdf

8. убанова Е.В., Демичева М.А. Развитие агропромышленного комплекса Калужской области // Аграрный вестник Верхневолжья. 2020. № 1 (30). С. 125134.

9. Климова Н.В., Трубачева Е.А. Факторы и направления инвестирования агропромышленного комплекса России // Экономика: вчера, сегодня, завтра. 2017. T. 7. № 6B. С. 217-230.

10. Ромодан Ю.О. Инвестиционная климат и привлекательность АПК: состояние, проблемы и пути решения // ИнноЦентр. 2014. № 1 (2). С. 31-36.

11. Губанова Е.В., Демичева М.А. Оценка инвестиционного потенциала агропромышленного комплекса Калужской области // Аудит и финансовый анализ. 2019. № 1. С. 108-113.

12. Грудкин А.А. Формирование инвестиционного потенциала агропромышленного комплекса Республики Крым // АПК: Экономика, управление. 2017. № 1. С. 19-27.

13. Морковкин Д.Е., Строев П.В., Шапошников А.И. Финансовая поддержка регионов как инструмент выравнивания бюджетной обеспеченности субъектов Российской Федерации // Финансы: теория и практика. 2019. Т. 23. № 4 (112). С. 57-68.

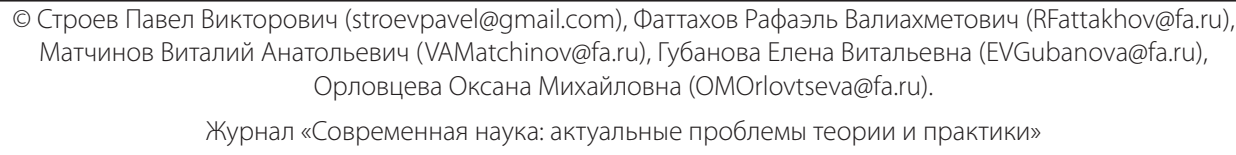

Журнал «Современная наука: актуальные проблемы теории и практики»

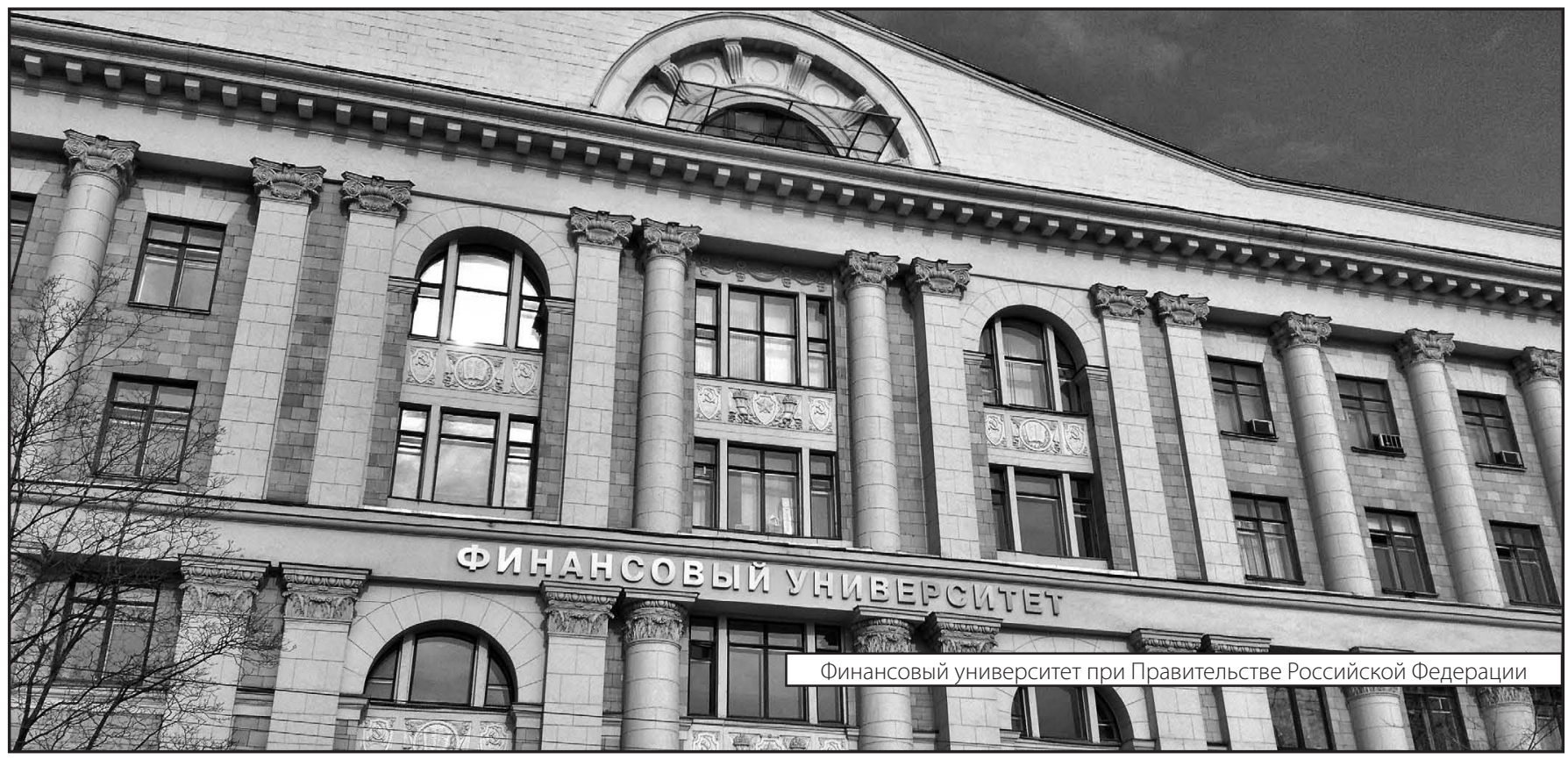

